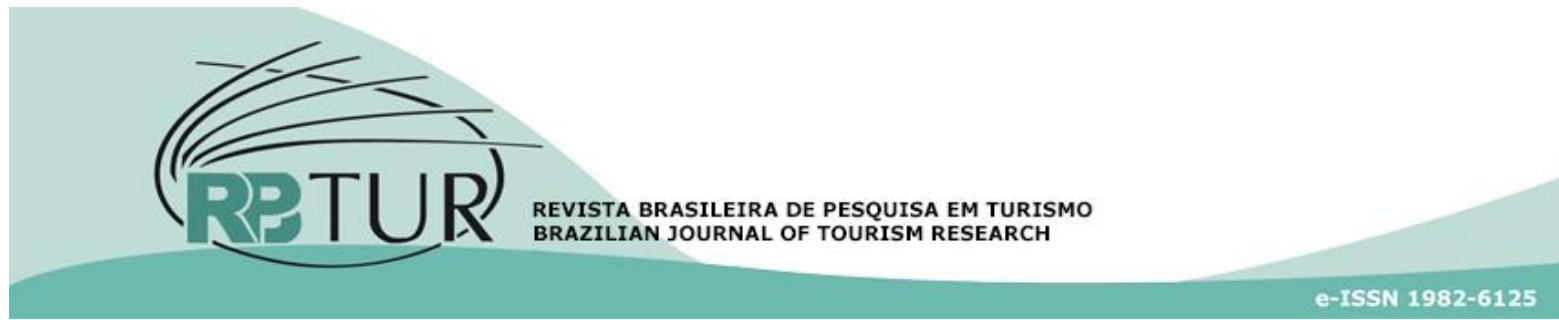

\title{
Artigos
}

\section{Fatores que influenciam a participação dos consumidores no Turismo Eletrônico}

\section{Factors that influence consumers' participation in Electronic Tourism}

\section{Factores que influyen la participación de los consumidores en el Turismo Electrónico}

\author{
Fernanda dos Santos; Guilherme Lerch Lunardi1; Cláudia Rodrigues Maia²; Edar da Silva Añaña² \\ 1 Universidade Federal do Rio Grande (FURG), Rio Grande, Rio Grande do Sul, Brasil. \\ 2Universidade Federal do Rio Grande do Sul, (UFRGS), Porto Alegre, Rio Grande do Sul, Brasil.
}

Palavras-chave:

Turismo eletrônico.

Comércio eletrônico.

Comportamento de compra.

Keywords:

Electronic tourism

E-commerce.

Buying behavior.
Resumo

Os recentes avanços nas Tecnologias da Informação e Comunicação (TIC) transformaram a indústria do turismo num setor essencial do comércio eletrônico. Nesse contexto, muitas empresas têm procurado entender os principais motivos que levam os consumidores a participar do turismo eletrônico (e-turismo). Assim, objetivou-se nesta pesquisa analisar diferentes fatores que influenciam a participação dos consumidores no e-turismo, seja escoIhendo um site, recomendando-o ou comprando produtos turísticos. 0 estudo se caracteriza como uma pesquisa survey, aplicada a uma amostra de 251 membros de grupos de turismo da Internet, cujo modelo proposto foi testado através da técnica de modelagem de equações estruturais. Os resultados apontaram como preditores da participação dos usuários no eturismo, a satisfação com experiências prévias e a qualidade dos produtos turísticos, sendo estes os aspectos que mais influenciam a intenção de comprar e recomendar o site. A satisfação com experiências prévias destaca-se como o principal preditor em ambas as situacões. As descobertas aqui obtidas aprofundam a compreensão acerca das atitudes do consumidor de serviços de turismo online, servindo de referência para gestores e pesquisadores interessados nesta temática.

Abstract

Recent advances in Information and Communication Technologies (ICT) transformed the tourism industry in a key sector for e-commerce. In such a context, many companies have sought to understand the main reasons that lead consumers to participate in electronic tourism (e-tourism). Thus, we aim to analyze different factors that influence the participation of consumers in e-tourism, by choosing a website, recommending it, or buying tourism products. We surveyed 251 participants enrolled in tourism discussion groups on the web, analyzing data through Structural Equation Modeling - SEM. Our results pointed out satisfaction with previous experiences and the quality of tourism products as the main drivers of customers' participation in e-tourism regarding the intention to buy and recommending the tourism website. Satisfaction with previous experiences stands out as the main predictor in both situations. We believe our findings will extend the understanding of consumer's attitudes to online tourism services aiding managers and researchers interested in this topic. 


\section{Palabras clave:}

Turismo electrónico.

Comercio electrónico.

Comportamiento de compra.

Revisado por pares.

Recebido em: 30/08/2019.

Aprovado em: 16/02/2020.

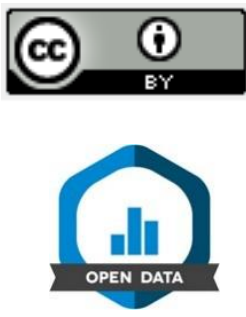

Resumen

Con los avanzos de las Tecnologías de Información y Comunicación (TIC), el turismo se ha convertido en un sector clave de comercio electrónico. En este contexto, muchas empresas han tratado de comprender las razones que llevan los consumidores a participar en el turismo electrónico (e-turismo). Por lo tanto, el objetivo de esta investigación fue analizar diferentes factores que influyen la participación de los consumidores en el turismo electrónico ya sea al elegir un sitio, recomendarlo o comprar productos turísticos. El estudio es una encuesta aplicada a una muestra de 251 miembros de grupos de turismo en Internet, cuyo modelo propuesto fue testado a través de la técnica de modelado de ecuaciones estructurales. Los resultados apuntan como predictores de la participación de los usuarios en el turismo electrónico, la satisfacción con las experiencias anteriores y la calidad de los productos turísticos, que son los aspectos que más influyen en la intención de comprar y recomendar el sitio. La satisfacción con experiencias previas se destaca como el principal predictor en ambas situaciones. Los resultados obtenidos aquí profundizan la comprensión de las actitudes de los consumidores de servicios electrónicos de turismo, y sirven de referencia a los gerentes e investigadores interesados en esta temática.

Como citar: Santos, F.: Lunardi, G. L.; Maia, C. R.; Anãnã, E. S. (2020). Fatores que influenciam a participação dos consumidores no Turismo Eletrônico. Revista Brasileira de Pesquisa em Turismo, São Paulo, 14 (2), p. 139-155, maio/ago. http://dx.doi.org/10.7784/rbtur.v14i2.1831

Dados abertos: http://dx.doi.org/10.17632/ddkzkc4d42.4

\section{INTRODUÇÃO}

A Tecnologia da Informação (TI) tem impactado as relações sociais, empresariais e organizacionais, mudando profundamente a atuação e o funcionamento de diversos negócios, dentre eles o Turismo. Conforme Marco, Gómez \& Sevilla (2018), a indústria do turismo sofreu uma grande transformação desde que a TI passou a ser utilizada neste setor, ainda na década de 1980, e especialmente após o advento da Internet, no final dos anos 1990. Tais avanços têm transformado o turismo em um dos setores-chave do comércio eletrônico (Ponte, Carvajal-Trujillo \& Escobar-Rodríguez, 2015), desempenhando papel fundamental na competitividade das organizações que atuam nesse segmento, assim como nos próprios destinos turísticos.

A integração da tecnologia com o turismo deu origem ao que vem sendo chamado de turismo eletrônico ou e-turismo, definido como a digitalização de todos os processos da cadeia de valor da indústria de turismo, viagens, hospitalidade e alimentação (Buhalis \& Deimezi, 2004). Segundo Buhalis \& Law (2008), o termo eturismo já vem sendo utilizado há mais de 25 anos, desde a conferência realizada em Innsbruck, Áustria, em 1994, sendo consolidado posteriormente alguns anos mais tarde, em 1998, quando um grupo de interesse que publicava regularmente sobre turismo e tecnologia estabeleceu o Journal of Information Technology \& Tourism (JITT). Entretanto, conforme Biz e Corrêa (2016), a pesquisa científica no Brasil sobre o e-turismo ainda é recente, e ganhou especial amplitude a partir da fundação da ANPTUR, em 2002.

Hoje, o setor de turismo é altamente dependente da informação, especialmente por seus produtos ou serviços só poderem ser efetivamente avaliados quando consumidos. E devido à intangibilidade desses serviços, maior é a necessidade de informação para o turista. Vários autores têm destacado que os produtos e serviços turísticos são perfeitamente adequados à venda online, por apresentarem um nível elevado de intangibilidade, envolvimento e diferenciação maior do que outros bens de consumo tangíveis, sendo consequentemente mais facilmente vendidos na web (Ponte, Carvajal-Trujillo \& Escobar-Rodrígues, 2015; Oneto, Ferreira, Giovannini e Silva, 2015; Silva, Mendes-Filho e Corrêa, 2017).

Segundo o Ministério do Turismo, os meios digitais têm se consolidado como a principal fonte de informações para turistas brasileiros e estrangeiros, que devido ao fácil acesso à Internet em quase todos os destinos brasileiros conseguem organizar suas viagens utilizando este veículo. A cada hora, internautas do mundo todo realizam em torno de 625 mil buscas sobre viagens, somente no site Google (Brasil, 2014). Dentre os turistas que visitaram o país por motivo de lazer, em 2017, 79,5\% não utilizaram agências de viagens tradicionais para a organização das suas viagens, e dos que visitaram por motivos de negócios, eventos ou 
convenções, 80,3\% fizeram uso apenas da Internet (Brasil, 2018). Portanto, admitindo-se o e-turismo como um tema recente e relevante para futuros estudos na área do Turismo, levanta-se a seguinte questão de pesquisa: Quais fatores têm influenciado a participação dos consumidores no e-turismo? A presente pesquisa analisa, sob a perspectiva do consumidor, os fatores que têm influenciado a participação dos consumidores no e-turismo, seja escolhendo um site de turismo online, adquirindo um ou mais produtos turísticos, ou ainda, recomendando o site a outras pessoas. 0 modelo proposto foi testado através da técnica de modelagem de equações estruturais, baseada nos mínimos quadrados parciais (PLS).

\section{REVISÃO DA LITERATURA}

Como forma de fundamentar o estudo, apresenta-se uma breve contextualização sobre a influência da TI no setor de turismo, denominado de turismo eletrônico (ou e-turismo), para depois apresentar os diferentes fatores que têm sido destacados na literatura como potenciais influenciadores da participação dos consumidores nesse tipo de comércio eletrônico. Ao final, apresentam-se as hipóteses do estudo e o modelo proposto.

\subsection{Turismo Eletrônico}

A economia do turismo no mundo atual tem sido amplamente impulsionada pela TI (Jaremen, 2016). Diferentes empresas ligadas a este setor, como operadoras de turismo, agências de viagens, agências de aluguel, cruzeiros e hotéis admitem o crescente impacto da tecnologia da informação nas suas atividades. A integração do turismo com a TI proporciona diferentes tipos de vantagem competitiva às empresas, uma vez que permite a criação de ferramentas de apoio aos gestores, para que adaptem rapidamente as ofertas às alterações provocadas pela globalização dos mercados, pela emergência de novos competidores e pela motivação dos turistas (Ramos, 2008).

Para Zhang, Fang, Wei, Ramsey, McCole \& Chen (2011), a complexidade dos modelos de negócios presentes no turismo requer o desenvolvimento constante de novos sistemas que proporcionem maior flexibilidade, automação, integração, armazenamento e colaboração entre turistas e fornecedores de produtos e serviços turísticos. Segundo Herrero, San Martín \& Hernández (2015), nas últimas décadas, houve uma explosão de plataformas web e mídias sociais disponíveis para todas as pessoas e organizações, e para publicação de conteúdo de qualquer tipo, incluindo os conteúdos turísticos. Além disso, o surgimento da Web 2.0 redefiniu a adoção do turismo online pelos consumidores, sendo esta definida como uma ampla variedade de aplicações eletrônicas (envolvendo, por exemplo, as redes sociais, os sites de análise, blogs, sites interativos e plataformas de compartilhamento de fotos e vídeos), que facilitam as interações entre os indivíduos e entre as empresas e os usuários (Ukpabi \& Karjaluoto, 2017), impactando diretamente nos resultados do setor.

0 turismo eletrônico envolve atividades que resultam na troca/busca de informações, reservas e compras de produtos turísticos online. De acordo com Buhalis \& Deimezi (2004), o e-turismo reflete a digitalização de todos os processos da cadeia de valor nas indústrias de turismo, viagens, hotelaria e alimentação. Em particular, ele pode ser considerado como a integração da atividade turística e da tecnologia da Internet; portanto, refere-se a todos os sistemas de negócio baseados na web, voltados para o turismo (Zhang et al., 2011). 0 e-turismo envolve atividades como reservas de hotel, compras pela Internet de passagens aéreas e escolha de destinos de viagens, seja através de um computador remoto ou dispositivo móvel. 0 uso dos dispositivos móveis, por exemplo, ganha relevância devido ao fato do turista estar viajando e poder buscar restaurantes ou outros serviços móveis pelos aplicativos disponíveis ou pela consulta local (Marco, Gómez \& Sevilla, 2018).

A maioria das inovações do setor de tecnologia da informação mudou a maneira como as empresas turísticas conduzem seus negócios, uma vez que o processo de compra dos serviços turísticos baseia-se especialmente na coleta de informações (Jaremen, 2016). Devido à maior disponibilidade de informações turísticas presentes nos meios eletrônicos, a Internet tem sido, segundo Marco, Gómez \& Sevilla (2018), propícia para que os turistas encontrem seu destino, sua acomodação, além de alguns serviços privados de aluguel, permitindo que organizem seus próprios pacotes turísticos. Especialmente para as empresas de 
turismo, a Internet ofereceu a possibilidade de disponibilizar informações e reservas para um grande número de consumidores a custos relativamente baixos, fornecendo uma importante ferramenta de comunicação entre fornecedores de turismo, intermediários e consumidores finais (Di Pietro, Di Virgilio \& Pantano, 2011).

Segundo Leung, Law, Van Hoof \& Buhalis (2013), os turistas se tornaram mais independentes e sofisticados e dispõem de uma ampla variedade de ferramentas para organizar suas viagens. Estas incluem sistemas de reserva e agências de viagens online (como Expedia), ferramentas de busca (como o Google), portais (como o site TripAdvisor), sites de comparação de preços (Decolar.com), assim como sites de compra coletiva, fornecedores individuais e sites intermediários. Buhalis \& Law (2008) identificaram o conhecimento dos consumidores como um dos principais tópicos de pesquisa no e-turismo. Como resultado dessas novas tecnologias, o novo turista é definido como um consumidor exigente, que depende mais das informações fornecidas pelos pares, com experiência prévia e informação sofisticada, que lhe permite buscar produtos personalizados. Assim, identificar rapidamente as necessidades e antecipar os desejos desses usuários é cada vez mais a tarefa prioritária das empresas e agências de turismo (Fernández-Poyatos \& Papí-Gálvez, 2017).

\subsection{Antecedentes da participação dos consumidores no e-Turismo}

Beldad, De Jong \& Steehouder (2010) realizaram uma revisão sistemática da literatura, cobrindo diferentes estudos empíricos sobre a confiança das pessoas e a adoção de serviços mediados por computador. Neste estudo, os resultados evidenciaram uma série de antecedentes possiveis de serem utilizados nos serviços eletrônicos. 0 autores propuseram, então, uma estrutura formada por três grupos de antecedentes: (i) os antecedentes baseados no cliente, como a experiência do usuário com a tecnologia utilizada para realizar a transação ou a tendência do usuário confiar nela; (ii) os antecedentes baseados no próprio site, envolvendo a qualidade do site usado ou a qualidade da informação disponibilizada no site; e (iii) os antecedentes baseados na empresa, como a reputação, a familiaridade com a empresa e o seu tamanho.

Filieri, Alguezaui \& McLeay (2015) e Agag \& El-Masry (2017), por sua vez, adaptaram o modelo de Beldad et al. (2010) para analisar os antecedentes da confiança dos consumidores no e-turismo. 0 estudo de Filieri et al. (2015) testou cinco antecedentes da confiança sobre o conteúdo gerado pelo consumidor (CGM), sendo eles: a credibilidade da fonte, a qualidade da informação, a qualidade do site, a satisfação do cliente e a experiência do usuário com o CGM. Como antecedentes da confiança baseados no cliente, incluíram a experiência do usuário (conhecimento e habilidades) no uso do CGM; como antecedentes baseados no site incluíram a qualidade do site, a qualidade da informação e a credibilidade da fonte percebida; e como antecedentes baseados na empresa incluíram a experiência dos usuários com o CGM. Os autores concluíram que todos os fatores mencionados, com exceção da credibilidade da fonte e da experiência do usuário, influenciam a confiança do consumidor em relação ao CGM.

Já o estudo de Agag \& El-Maskry (2017) testou um modelo formado por sete antecedentes da confiança dos consumidores em relação a sites de viagens online, sendo eles: a experiência do consumidor, a propensão à confiança, a reputação, o tamanho do site, a facilidade de uso, a utilidade percebida e a qualidade do site. Os resultados confirmaram que todos os fatores mencionados, com exceção da experiência do consumidor, influenciam a confiança do usuário em relação aos sites de viagens online. A pesquisa revelou, ainda, que a atitude dos consumidores em relação ao site é o principal determinante da intenção de compra online.

Buhalis \& Law (2008) também deram ênfase à busca de informações e à forma como a tecnologia modifica o comportamento dos turistas. Nesse contexto, destacam-se os comentários, avaliações e recomendações de terceiros como as trocas de experiência e informações, tanto positivas quanto negativas. Esta comunicação online entre usuários individuais, através do compartilhamento de conhecimento e experiência de um novo produto também influencia a confiança (Hajli, Hajli \& Khani, 2013). Segundo Bassani, Milan, Lazzari e De Toni (2018), cada informação que o consumidor recebe e interpreta serve de base para que ele faça avaliações sobre um determinado produto. Estes fatores, baseados em fontes de terceiros - também chamados de boca-a-boca eletrônico (do inglês, electronic word-of-mouth ou e-WOM), igualmente representariam importantes antecedentes da participação dos consumidores no e-turismo. 
Conforme Xiang, Magnini \& Fesenmaier (2015), os produtos de viagem tradicionais, como passagens aéreas e hospedagem continuam a dominar o mercado de viagens online. Nesse sentido, a percepção da qualidade do produto, serviço ou pacote turístico que o consumidor deseja comprar é bastante relevante na esfera do e-turismo. Segundo Dedeke (2016), na literatura existente sobre esta temática encontram-se evidências tanto teóricas quanto empíricas que mostram que a percepção da qualidade do produto influencia a intenção de compra dos consumidores. Neste aspecto, a disponibilidade de fotos de produtos turísticos, por exemplo, afetaria a disposição do cliente em realizar os negócios em um site (Dedeke, 2016). Assim, os sites deveriam incorporar fotografias e outros elementos audiovisuais que permitissem aos usuários reduzir a intangibilidade do serviço e, portanto, minimizar o risco percebido (Herrero et al., 2015). Nesse sentido, o fator baseado na percepção da qualidade do produto também pode representar um importante antecedente da participação dos consumidores no e-turismo.

Assim, com base na literatura, foram identificados diferentes antecedentes que podem influenciar a participação dos consumidores no turismo eletrônico, os quais podem ser agrupados em antecedentes baseados no website (Qualidade do Site), na empresa (Reputação), no consumidor (Satisfação com experiências prévias), na informação de terceiros (e-WOM) e no produto turístico oferecido (Qualidade do produto). A partir desse levantamento, justifica-se a proposição de hipóteses a serem testadas empiricamente, as quais são destacadas na próxima seção, juntamente com a sua fundamentação teórica.

\subsection{Hipóteses}

Conforme Alcántara-Pilar, Blanco-Encomienda, Armenski \& Del Barrio-García (2018), os sites se tornaram o meio mais importante de promoção do turismo atualmente, podendo provocar uma percepção positiva sobre um determinado destino de viagem. 0 uso dos sites fornece a primeira impressão do fornecedor, solidificando as impressões iniciais do consumidor. Portanto, se os consumidores perceberem que o site é de alta qualidade, é provável que tenham uma atitude mais positiva sobre a competência, integridade e benevolência do varejista online, desenvolvendo uma disposição para comprar produtos neste site (Chang $\&$ Chen, 2008), ou pelo menos retornar ao mesmo futuramente. Ainda para os autores, a qualidade do site é definida como a avaliação que os usuários fazem sobre os recursos de um site e se esses atendem as suas necessidades. No contexto do e-turismo, a qualidade de um site se refere às percepções dos consumidores sobre a sua disponibilidade, adaptabilidade e tempo de resposta (Filieri et al., 2015). Com base nas afirmações acima, propõe-se a seguinte hipótese:

H1: A qualidade do website afeta positivamente a participação dos usuários da Internet no e-turismo.

Para Rodríguez-Díaz, Rodríguez-Voltes \& Rodríguez-Voltes (2018), a reputação online é um elemento estratégico da competitividade que influencia diretamente o comportamento de compra dos clientes, especialmente em setores onde a comunicação realizada pela Internet é essencial para o desenvolvimento do negócio. Huang \& Benyoucef (2013) sugerem que as agências de viagens precisam construir vantagens referentes a sua reputação, para ganhar competitividade no mercado. Portanto, é importante que a agência de viagem e seus gerentes gozem de boa reputação para que os clientes confiem nos produtos de viagem que Ihes são sugeridos (Keh \& Xie, 2009), uma vez que isto pode ser um fator preponderante na escolha de um produto ou serviço em um destino turístico (Santos, Souza Neto, Pereira, Gândara e Silva, 2016). Assim, propõe-se a seguinte hipótese:

H2: A reputação afeta positivamente a participação dos usuários da Internet no e-turismo.

Conforme Bagozzi (1981), a experiência anterior pode ser um importante determinante da mudança de comportamento e pode moldar as intenções em relação a um destino ou escolha de um provedor de serviços turísticos oferecidos na Internet. A experiência de passeio avaliada favoravelmente pelos viajantes apresenta uma forte relação com a satisfação dos viajantes e suas intenções comportamentais (Antón, Camarero, \& Garcia, 2014). No contexto online, Lehto, Kim \& Morrison (2006) mostraram que as experiências prévias com o site da empresa e o conhecimento de um determinado destino influenciam tanto o tipo de conteúdo pesquisado quanto o tempo gasto durante uma sessão de busca de informações online para o planejamento da viagem. Para Carvalho, Ferreira, Kanazawa, Machado e Giraldi (2016), a experiência positiva com websites influencia na formação da imagem de um destino turístico e na intenção de visitá-lo. A satisfação 
do consumidor é medida como a satisfação geral de um cliente, que é baseada nas experiências acumuladas com uma empresa, um produto ou um serviço, não sendo a satisfação resultante de uma transação específica, e sim uma avaliação global do histórico de relacionamento entre as partes (Olsen \& Johnson, 2003). Marchiori e Cantoni (2015), por sua vez, identificaram que a falta de experiência com uma dada empresa pode afetar a desconfirmação das expectativas, após a exposição ao conteúdo online. Assim, com base nas informações acima, propõe-se a seguinte hipótese:

H3: A satisfação com experiências prévias afeta positivamente a participação dos usuários da Internet no e-turismo.

Para Rodríguez-Díaz et al. (2018), o boca-a-boca tradicional foi substituído pelo boca-a-boca online (ou eWOM), tendo este um impacto ainda maior e mais imediato nas expectativas dos clientes e nos resultados do negócio. Herrero et al. (2015) apontam que no setor de turismo e hospitalidade, o e-WOM tem especial relevância para os usuários durante a fase de pré-compra (ou seja, na busca de informações e na escolha final). Portanto, pode ser visto como uma variável que depende da satisfação dos consumidores com o site de turismo e, por sua vez, mostra-se um antecedente da intenção de recomendar um determinado produto ou serviço. Para Öz (2015), as empresas de turismo devem dar especial importância às mensagens de mídia social. Algumas dessas mensagens podem ser avaliadas como uma forma de e-WOM e podem potencialmente influenciar milhares de consumidores em todo o mundo. Para Nilashi, Ibrahim, Yadegaridehkordi, Samad, Akbari \& Alizadeh (2018), a imagem de um destino turístico é afetada pelo conteúdo gerado e postado pelos próprios viajantes e turistas, além das informações controladas pelos agentes. Segundo Herrero et al. (2015), o conteúdo gerado por outras pessoas é uma fonte de informação tão importante quanto a informação oficial disponível sobre um destino turístico. Para Santos e Perinotto (2016), o turista em potencial sempre busca informações a respeito do seu possível destino e que, na maioria das vezes, não seja de caráter promocional, na busca de compreender a realidade local, fugindo da "influência" das ações promocionais. E ao ter experiências marcantes, estas se tornam critérios que permanecem ativos na memória, e são propagadas através do e-WOM (Cechinel \& Santos, 2018). Assim, propõe-se a seguinte hipótese:

H4: O e-WOM afeta positivamente a participação dos usuários da Internet no e-turismo.

Por fim, Santos et al. (2016) descrevem que o comportamento do consumidor vem mudando com o passar do tempo. Atualmente, ele não compra um produto apenas para atender as suas necessidades, estando o consumo relacionado muitas vezes aos sentimentos e emoções que a experiência que o produto ou serviço é capaz de proporcionar. Para Dedeke (2016), a qualidade percebida do produto ou serviço turístico é definida como a impressão do cliente em potencial sobre o nível de qualidade que um produto ou serviço é capaz de oferecer, se comprado. Produtos turísticos geralmente são comprados sem que se possa experimentá-los, portanto a experiência da compra online não difere muito da compra offline (Cosma, Bota \& Tutunea, 2012). Assim, em um ambiente de turismo, entender como as pessoas escolhem entre os vários produtos de viagem pode melhorar o desempenho das vendas e o sucesso do marketing. No contexto do eturismo, mais especificamente, a qualidade esperada do produto é um fator de vantagem competitiva, por estar relacionada à intenção de compra (Dedeke, 2016). Assim, levanta-se a seguinte hipótese:

H5: A qualidade do produto afeta positivamente a participação dos usuários da Internet no e-turismo.

A Figura 1 apresenta o modelo de pesquisa proposto neste estudo, contendo as cinco hipóteses levantadas, as quais foram subdivididas em relação à intenção de compra no site de turismo e o comportamento de recomendá-lo. 0 modelo causal proposto pretende contribuir com os trabalhos desenvolvidos por Beldad et al. (2010), Filieri et al. (2015) e Agag \& El-Maskry (2017), ao incluir novas variáveis baseadas no produto turístico oferecido (Qualidade do Produto) e na informação de terceiros (e-WOM), além de analisar tais antecedentes como preditores da participação dos usuários no e-turismo, diferentemente dos trabalhos anteriores, cujo foco principal abordava a confiança no site. Os detalhes referentes à metodologia empregada no estudo são apresentados a seguir. 


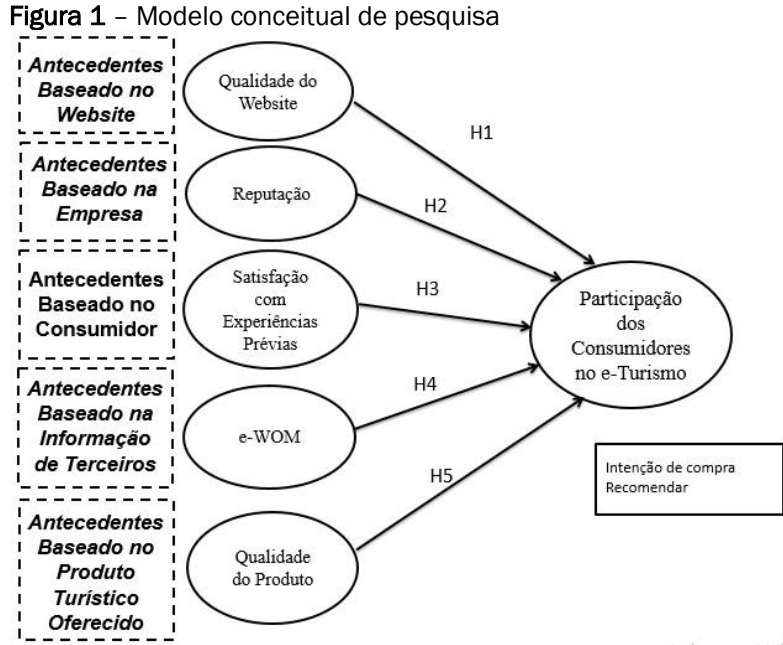

\section{METODOLOGIA}

O estudo se caracteriza como uma pesquisa quantitativa, de caráter exploratório-descritivo, operacionalizada através de uma pesquisa survey, aplicada a 273 participantes da rede social Facebook. Os respondentes fazem parte de 36 grupos online de turismo que foram contatados, e que tinham como foco alguma atividade relacionada ao turismo, como: dicas de locais para visitar, passagens aéreas, hotéis, mochileiros, relatos de viagem e etc. Desse total, 22 respondentes foram excluídos por mau preenchimento do instrumento (alguns por deixarem muitas questões em branco, e outros por concentrarem suas respostas em um único ponto da escala), restando uma amostra válida de 251 casos. A cada respondente foi solicitado que selecionasse dentre as suas últimas experiências de compra ou pesquisa realizadas em sites de turismo online, uma para responder o instrumento proposto. A coleta de dados ocorreu em maio de 2019.

Como forma de coleta de dados, foi elaborado um questionário com questões estruturadas, as quais foram operacionalizadas a partir de medidas validadas em estudos prévios, sendo os seus itens adaptados para a presente pesquisa. Inicialmente, as questões foram traduzidas do inglês para o português e, em seguida, traduzidas novamente ao inglês (tradução reversa). As diferenças encontradas entre as duas versões foram discutidas entre os autores da pesquisa para minimizar possíveis inconsistências quanto ao seu significado, sendo posteriormente avaliadas por cinco especialistas, todos doutores atuantes nas áreas de Administração, Turismo e Estatística.

Para operacionalização dos itens referentes ao processo de compra ou pesquisa de produtos no e-turismo, adotou-se uma escala tipo Likert de sete pontos, variando de discordo totalmente (1) a concordo totalmente (7). A mesma escala foi utilizada para avaliar a participação dos usuários no e-turismo, quanto a sua intenção de comprar e recomendar o site - medidas também adaptadas de estudos já validados. Ao instrumento foram acrescentadas nove questões referentes ao perfil dos respondentes (gênero, idade, escolaridade, estado civil, estado de residência, renda pessoal, sites de turismo online que costuma acessar para realizar suas compras ou pesquisas, frequência com que realiza viagens de turismo e quantas vezes já realizou compras ou reservas online de produtos turísticos), e nove questões relacionadas ao processo de compra e/ou pesquisa no site de turismo avaliado (tipo de produto, site utilizado, frequência que utiliza este site para suas compras/pesquisas, se realizou a viagem sozinho ou acompanhado, o motivo da viagem, o dispositivo utilizado para busca/compra, a faixa de preço do produto, se o mesmo foi comprado ou apenas pesquisado e a comparação do preço encontrado neste site em relação aos concorrentes).

O instrumento de coleta foi previamente testado junto a 27 alunos de Mestrado, de um Programa de PósGraduação em Administração. 0 pré-teste teve o objetivo de identificar possíveis problemas de formatação e/ou compreensão das questões incluídas no questionário, sendo este aplicado a um perfil próximo da amostra pretendida. Após pequenos ajustes no instrumento, foram enviadas mensagens pelo Facebook convidando diferentes membros da rede, pertencentes a grupos de turismo, a participar de uma pesquisa sobre turismo eletrônico, solicitando aos mesmos que acessassem o questionário através de um link e, se possível, compartilhassem o convite com sua rede de amigos e conhecidos. Como critérios de inclusão foi definido que os participantes deveriam ser maiores de idade e ter pesquisado ou realizado compras ou 
pesquisas em sites de turismo online nos últimos doze meses. A amostra classifica-se como não probabilística, sendo os respondentes selecionados por conveniência.

\subsection{Validação do Instrumento}

Após os procedimentos de coleta, procedeu-se à validação das escalas utilizadas. Inicialmente, realizou-se a análise fatorial no bloco, analisando-se as questões referentes a cada constructo de forma individual. Todas as variáveis confirmaram a sua formação original, sem a necessidade de eliminação de qualquer item. Foram calculados, ainda, os coeficientes do Alfa de Cronbach para cada fator, os quais apresentaram valores entre 0,78 e 0,95, apontando uma boa consistência interna das escalas utilizadas (Hair et al., 2009).

Em seguida, empregou-se a técnica de modelagem de equações estruturais baseada na variância, através do software SmartPLS 3.0 (Partial Least Squares). O PLS vem sendo amplamente utilizado nas áreas de Marketing, Estratégia, Sistemas de Informação e Turismo (Valle \& Assaker, 2016; Hair Jr. et al., 2019), especialmente por ser apropriado para aplicações que envolvem predição e construção de teoria, além de ser adequado para dados que não possuem necessariamente uma distribuição normal, o que é exigido pelas técnicas de modelagem de equações estruturais baseadas em covariância.

Com base nessa metodologia, os dados são analisados e interpretados em duas etapas: (1) a avaliação do modelo de mensuração e (2) a avaliação do modelo estrutural. Para se avaliar o modelo de mensuração, foram verificadas as validades discriminante e convergente do modelo através da análise fatorial confirmatória (AFC) (Tabela 1). A validade discriminante é estabelecida quando um indicador apresenta a carga fatorial em seu construto original maior do que todas as suas cargas cruzadas com outros construtos. Espera-se que as cargas fatoriais atinjam um mínimo de 0,70 no seu respectivo fator, e cargas mais baixas nos demais fatores. Para isso, foram avaliadas as cargas fatoriais de todos os construtos do modelo, o qual sugeriu a eliminação de um item, presente no construto Reputação por não atender este critério. Gerou-se novamente o algoritmo PLS, e a solução confirmou todos os itens apresentando elevadas cargas fatoriais (superiores ou iguais a 0,70, conforme sugere a literatura), sendo estatisticamente significativas ao nível de $5 \%$, nos seus respectivos constructos (indicando confiabilidade dos itens).

Tabela 1 - Análise Fatorial Confirmatória (AFC)

\begin{tabular}{|c|c|c|c|c|c|c|c|}
\hline & e-Wom & $\begin{array}{l}\text { Satisfação c/ } \\
\text { experiências }\end{array}$ & $\begin{array}{l}\text { Intenção } \\
\text { Comprar }\end{array}$ & $\begin{array}{l}\text { Qualidade } \\
\text { Produto }\end{array}$ & $\begin{array}{l}\text { Recomen- } \\
\text { dação }\end{array}$ & Reputação & $\begin{array}{l}\text { Qualidade } \\
\text { do Site }\end{array}$ \\
\hline EWOM1 & ,835 & ,468 & ,381 & ,384 & ,242 & ,439 & ,339 \\
\hline EWOM2 & ,836 & ,396 & ,377 &, 502 & ,316 &, 532 & ,390 \\
\hline EWOM3 & ,862 & ,395 & ,368 & ,443 & ,291 & ,436 & ,347 \\
\hline EWOM4 & ,838 & ,366 & ,376 &, 503 & ,266 &, 522 & ,461 \\
\hline EXP1 & ,356 & ,847 & ,646 & ,457 & ,438 & ,518 & ,447 \\
\hline EXP2 & ,424 & ,875 & ,606 &, 542 & ,425 &, 596 & ,615 \\
\hline EXP3 & ,444 & ,887 & ,664 & ,637 &, 500 & ,603 & ,585 \\
\hline EXP4 & ,449 & ,873 & ,707 & ,641 &, 535 & ,678 & ,602 \\
\hline INT1 & ,404 & ,744 & ,903 & ,604 & ,702 & ,632 &, 579 \\
\hline INT2 & ,370 & ,600 & ,891 &, 536 & ,641 & ,491 & ,471 \\
\hline INT3 & ,432 & ,697 & ,923 & ,610 & ,639 & ,607 &, 541 \\
\hline PROD1 & ,384 & ,491 & ,480 &, 754 & ,341 & ,468 &, 540 \\
\hline PROD2 & ,399 & ,590 & ,510 & ,777 & ,380 &, 568 &, 554 \\
\hline PROD3 & ,490 &, 548 &, 541 & ,800 & ,430 &, 457 &, 510 \\
\hline PROD4 &, 433 & ,441 &, 501 & ,813 & ,419 &, 473 &, 521 \\
\hline REC1 & ,302 & ,479 & ,670 & ,453 & ,940 & ,430 & ,331 \\
\hline REC2 &, 350 &, 548 & ,686 &, 462 & ,956 & ,485 & ,380 \\
\hline REC3 & ,295 &, 536 & ,728 &, 515 & ,960 & ,441 & ,386 \\
\hline REPUT2 &, 517 &, 594 &, 538 &, 543 & ,382 & ,884 &, 544 \\
\hline REPUT3 & ,446 & ,598 & ,569 &, 552 & ,444 & ,864 &, 507 \\
\hline REPUT4 &, 476 & ,532 & ,495 & ,460 &, 357 &, 747 & ,473 \\
\hline SITE1 & ,352 &, 534 &, 460 & ,462 & ,296 & ,449 & ,798 \\
\hline SITE2 & ,408 & ,589 & ,529 & ,642 & ,343 & ,601 & ,822 \\
\hline SITE3 & ,271 & ,416 &, 371 &, 443 & ,268 & ,451 & ,721 \\
\hline SITE4 &, 373 & ,455 & ,455 &, 528 & ,284 & ,378 &, 769 \\
\hline
\end{tabular}


A validade convergente dos construtos foi avaliada analisando-se o valor das cargas fatoriais e usando-se 0 critério da variância média esperada (do inglês, Average Variance Extracted - AVE), cujos valores excederam o limite mínimo de 0,50 (Tabela 2). Tanto as cargas fatoriais quanto os valores de AVE servem de base para assegurar que os construtos do modelo proposto demonstram validade convergente. A validade discriminante ainda foi verificada pelo critério de Fornell e Larcker, em que a raiz quadrada da AVE deve ser maior que as correlações entre os demais construtos do modelo (destacado em negrito na diagonal). Complementarmente, utilizou-se o critério da razão multitraço-monotraço (ou HTMT), no qual se espera que a relação entre os constructos seja menor que 0,90 , o que também foi atendido pela pesquisa (Hair et al., 2017).

Tabela 2 - Variância compartilhada, correlações e confiabilidade dos construtos

\begin{tabular}{lccccccccccc}
\hline & Média & Alfa & CR & AVE & $\begin{array}{l}\text { Intenção } \\
\text { Comprar }\end{array}$ & $\begin{array}{l}\text { Sat. Exp } \\
\text { Prévia }\end{array}$ & $\begin{array}{l}\text { Qual. } \\
\text { Produto }\end{array}$ & $\begin{array}{l}\text { Reco- } \\
\text { mendar }\end{array}$ & Reput. & $\begin{array}{l}\text { Quali. } \\
\text { Site }\end{array}$ & eWom \\
\hline Int. Comprar & 6,08 &, 891 &, 932 &, 821 &, 906 & & & & & & \\
Exper. Prévia & 6,32 &, 894 &, 926 &, 758 &, 756 &, 871 & & & & \\
Qual. Produto & 5,84 &, 794 &, 866 &, 618 &, 647 &, 658 &, 786 & & & \\
Recomendar & 5,74 &, 948 &, 967 &, 906 &, 730 &, 548 &, 501 &, 952 & & \\
Reputação & 6,35 &, 778 &, 872 &, 696 &, 642 &, 690 &, 624 &, 475 &, 834 & & \\
Qual. Site & 6,08 &, 783 &, 860 &, 605 &, 589 &, 647 &, 674 &, 385 &, 610 &, 778 & \\
e-Wom & 5,93 &, 864 &, 907 &, 710 &, 445 &, 482 &, 544 &, 332 &, 573 &, 456 &, 843 \\
\hline
\end{tabular}

Avaliou-se, ainda, a fidedignidade das escalas através da confiabilidade composta (do inglês, Composite Reliability - CR) e do alfa de Cronbach, como indicado na Tabela 2. Os escores de ambos os testes para todos os construtos excederam o limite mínimo de 0,70 , indicando uma boa confiabilidade das escalas. Por fim, avaliou-se a presença de multicolinearidade entre as variáveis independentes do modelo usando o fator de inflação de variância (VIF), cujos escores individuais ficaram entre 1,631 e 2,437, indicando que a multicolinearidade não é um problema neste estudo (Hair Jr. et al., 2014). As questões aplicadas no questionário, podem ser visualizadas no Anexo 1.

\section{RESULTADOS E DISCUSSÃO}

De modo a se caracterizar a amostra do estudo, destacam-se as principais características dos 251 participantes. Quanto ao gênero, $170(67,7 \%)$ mulheres e 81 (32,3\%) homens responderam à pesquisa. As faixas de idade predominantes concentram-se entre 20 e 30 anos (45,8\%) e entre 31 e 40 anos (33,1\%). Quanto ao estado civil, solteiros (55\%), seguidos de casados $(31,9 \%)$ representam a grande maioria da amostra. As faixas de renda predominantes por pessoa concentram-se entre 1 e 3 salários mínimos $(37,5 \%)$ e entre 3 e 5 salários mínimos (21,1\%). Em relação à escolaridade, 30,7\% possuem graduação e 49,8\% pósgraduação. Os respondentes concentram-se, em sua maioria, nos estados do Rio Grande do Sul ( $n=129$; 51,4\%), São Paulo ( $n=42 ; 16,7 \%)$ e Santa Catarina $(n=19 ; 7,6 \%)$. Do total de respondentes, $94 \%$ efetivaram a compra do produto turístico pesquisado, enquanto $6 \%$ realizaram apenas a busca do produto turístico no site, mas não concluíram a compra.

Com relação às questões referentes aos hábitos associados ao turismo, de forma resumida, 59,9\% tem o hábito de realizar viagens de turismo de 1 a 3 vezes ao ano. Em relação à frequência de compra de produtos turísticos pela Internet, $44,2 \%$ afirmam ter adquirido produtos de turismo mais de nove vezes. Outro dado relevante é sobre os sites de turismo eletrônico mais utilizados para realizar as suas compras ou buscas online, destacando-se o Booking.com (74,1\%), seguido de Decolar (57\%) e TripAdvisor (40,2\%). Além disso, $45,8 \%$ dos respondentes afirmaram usar outros sites relacionados ao turismo. Dentre os produtos comprados/pesquisados, escolhidos pelos respondentes para fazer a avaliação, 50,6\% escolheram hospedagem e $39,8 \%$ passagens aéreas. Quanto ao número de vezes que já realizaram compras no site avaliado, $45,8 \%$ compraram até três vezes, $24,7 \%$ de 4 a 5 vezes e $22,4 \%$ afirmaram ter comprado mais de dez vezes.

Em relação à viagem pesquisada, $28,3 \%$ planejavam viajar sozinho, enquanto os demais $(71,7 \%)$ consideraram viajar acompanhados por amigos, família ou namorado(a)/esposo(a). 0 dispositivo utilizado 
para fazer a busca ou a compra dos produtos se deu pelo uso conjunto do smartphone e do notebook/desktop (41,4\%), seguido pelo uso único do notebook/desktop (38,6\%), enquanto $18,7 \%$ afirmaram usar apenas o smartphone. O valor médio aproximado gasto com o produto turístico comprado/pesquisado foi de $\mathrm{R} \$ 1.923,00$ (sendo que mais de 60,1\% da amostra afirmaram ter gasto mais de $\mathrm{R} \$ 1.000,00$ na compra efetivada). Comparado aos produtos oferecidos em outros sites de turismo, $54,2 \%$ afirmaram que o site escolhido apresentou preço um pouco mais barato, $22,7 \%$ bem mais barato e para $15,9 \%$ o preço foi praticamente o mesmo. Do total de respondentes, $84,9 \%$ realizaram suas viagens por motivo de lazer/passeio.

De modo a se estimar o tamanho mínimo da amostra, foi utilizado o software G*Power 3.1.9.4. Para isso, foram observados os parâmetros sugeridos por Hair et al. (2014) para cálculo do poder estatístico (0.80) e tamanho do efeito ( $\left.f^{2}=0.15\right)$, o que exigiu uma amostra mínima de 92 casos, indicando que o tamanho total da amostra do estudo é adequado.

De modo a se analisar o modelo estrutural, também se utilizou o software SmartPLS 3.0, através da técnica de bootstrapping com 5.000 amostras, avaliando a aderência geral do modelo, bem como de seus parâmetros. A Tabela 3 apresenta os resultados do modelo e dos testes de hipóteses.

Tabela 3 - Resultado das Equações Estruturais

\begin{tabular}{|c|c|c|c|}
\hline Hipóteses & Relações & $\mathrm{r}$ & t-values \\
\hline $\mathrm{H} 1 \mathrm{a}$ & Qualidade do Website $\rightarrow$ Intenção de Compra & 0,05 & $0,63^{n s}$ \\
\hline $\mathrm{H} 1 \mathrm{~b}$ & Qualidade do Website $\rightarrow$ Recomendar & $-0,09$ & $1,14^{\text {ns }}$ \\
\hline $\mathrm{H} 2 \mathrm{a}$ & Reputação $\rightarrow$ Intenção de Compra & 0,16 & 1,59 ns \\
\hline $\mathrm{H} 2 \mathrm{~b}$ & Reputação $\rightarrow$ Recomendar & 0,14 & 1,59 ns \\
\hline HЗа & Satisfação com experiências prévias $\rightarrow$ Intenção de Compra & 0,49 & $4,61 * * *$ \\
\hline $\mathrm{H} 3 \mathrm{~b}$ & Satisfação com experiências prévias $\rightarrow$ Recomendar & 0,35 & $4,51 * * *$ \\
\hline $\mathrm{H} 4 \mathrm{a}$ & e-WOM $\rightarrow$ Intenção de Compra & $-0,01$ & $0,15^{\text {ns }}$ \\
\hline $\mathrm{H} 4 \mathrm{~b}$ & e-WOM $\rightarrow$ Recomendar & $-0,01$ & $0,15^{\text {ns }}$ \\
\hline $\mathrm{H} 5 \mathrm{a}$ & Qualidade do produto $\rightarrow$ Intenção de Compra & 0,20 & $2,96 * *$ \\
\hline $\mathrm{H} 5 \mathrm{~b}$ & Qualidade do produto $\rightarrow$ Recomendar & 0,25 & $2,84 * *$ \\
\hline \multicolumn{4}{|c|}{ Variância explicada $\left(R^{2}\right)$} \\
\hline \multicolumn{2}{|c|}{ Intenção de compra } & \multicolumn{2}{|l|}{$62,4 \%$} \\
\hline \multicolumn{2}{|c|}{ Recomendar } & \multicolumn{2}{|l|}{$34,6 \%$} \\
\hline
\end{tabular}

Legenda: $p>0,05=$ ns (Não Significativo); $p<0,05=* ; p<0,01=* * ; p<0,001=* * *$.

A partir dos resultados obtidos, pôde-se perceber que apenas a Satisfação com experiências prévias $(\beta=0,49, p$ $<0,000 ; \beta=0,35 ; p<0,000)$ e a Qualidade do Produto $(\beta=0,20 ; p<0,01 ; \beta=0,25 ; p<0,01)$ mostraram-se como as variáveis independentes presentes no modelo que influenciam de forma positiva e significativa a participação dos consumidores no turismo eletrônico, tanto na intenção de comprar quanto de recomendar sendo a satisfação com as experiências prévias a principal variável preditora do modelo, em ambas as relações causais testadas. 0 modelo explica $62,4 \%$ da variância da variável dependente Intenção de compra, o que representa um elevado grau de explicação e poder de predição; e 34,6\% da variação da variável dependente Recomendar, indicando um moderado grau de explicação. Nesse sentido, constata-se que somente as hipóteses H3 e H5 foram confirmadas, sugerindo que a participação dos consumidores no e-turismo é influenciada especialmente pelos antecedentes baseados no consumidor e no produto turístico oferecido. As demais hipóteses $(\mathrm{H} 1, \mathrm{H} 2 \mathrm{e} \mathrm{H} 4)$ foram rejeitadas, evidenciando que os antecedentes baseados no website, na empresa e na informação de terceiros não influenciam significativamente a participação dos consumidores no e-turismo.

Conforme Forgas-Coll, Palau-Saumell, Matute \& Tárrega (2017), a experiência do turista está diretamente e positivamente relacionada com suas intenções comportamentais, sendo considerada um importante elemento para a sua participação no e-turismo, onde os usuários consideram as suas experiências anteriores com a empresa como relevantes para a sua decisão de compra e de recomendar o site a outras pessoas, sejam elas conhecidas ou não.

Esses resultados corroboram estudos anteriores, que concluíram que a experiência passada retida na memória de um indivíduo é uma valiosa fonte de informação, sendo considerada altamente confiável, e que quanto maior o nível de satisfação com a experiência turística anterior, mais favoravelmente será o comportamento futuro deste turista (Sharma \& Nayak, 2019), tanto em relação à empresa quanto ao destino selecionado. 
Identificou-se no estudo que a satisfação favorável com as experiências vividas pelos usuários do e-turismo possui uma relação efetiva na sua intenção comportamental, seja revisitando ou recomendando o site a outros usuários. Da mesma forma, Alves, Stefanini e Moretti (2018) também confirmaram em sua pesquisa que o nível de experiência do cliente com uma dada empresa ou serviço/produto afeta positivamente sua intenção de repetir essa compra e até mesmo recomendá-la. Xia, Zhang \& Zhang (2018) ainda sugerem que a avaliação que os consumidores fazem com relação as suas experiências prévias com uma empresa de turismo contribuem positivamente para a formação da imagem global, tanto da empresa quanto do destino selecionado.

Da mesma forma, a percepção dos consumidores quanto à qualidade percebida do produto turístico, em termos de atratividade, qualidade, elaboração e experiências marcantes influenciarão a intenção de compra desse consumidor, assim como a recomendação da empresa ou site. De modo geral, os consumidores ainda sentem certo grau de ansiedade com relação à compra de produtos ou serviços online, dentre os quais estão os produtos turísticos (Chang \& Chen, 2008). Segundo Kim, Kandampully \& Bilgihan (2018), os consumidores constroem um relacionamento de apego emocional a um produto conceitualmente semelhante ao apego emocional desenvolvido entre as pessoas. Assim, é desejável que os sites de serviços de turismo online possam fornecer aos seus clientes informações detalhadas sobre os seus produtos, de modo a facilitar o planejamento de itinerários, a reserva de produtos turísticos, além, é claro, de oferecer uma variedade de pacotes, serviços e opções de valor agregado (Liao \& Shi, 2017).

O novo turista é definido como um consumidor exigente, que depende de informações e busca por produtos personalizados. Identificar rapidamente as necessidades e antecipar os desejos desses usuários deve ser tarefa cada vez mais prioritária das empresas e agências de turismo (Fernández-Poyatos \& Papí-Gálvez, 2017). Segundo Dedeke (2016), a qualidade percebida do produto turístico se mostra um fator determinante da vantagem competitiva de empresas que atuam no e-turismo, estando positivamente relacionada com a intenção de compra dos consumidores. Conforme Sullivan \& Kim (2018), os fatores de avaliação do produto também se mostram como importantes atributos para a determinação da intenção de recompra e de recomendar a empresa, o site ou o destino turístico selecionado.

\section{CONSIDERAÇÕES FINAIS}

Com o avanço das diferentes tecnologias de informação e comunicação (TIC), o turismo passou a ser um dos setores-chave do comércio eletrônico. Em geral, as empresas de turismo têm procurado entender as motivações que têm levado os consumidores a participar do turismo eletrônico. Em termos acadêmicos, pesquisas dessa natureza têm se tornado alvo relevante nos estudos internacionais. A literatura sobre o e-turismo é bastante ampla, principalmente em países desenvolvidos, como Estados Unidos, Canadá e União Europeia. Já em países em desenvolvimento, como no caso do Brasil, as pesquisas publicadas, embora existentes, são mais escassas, o que ressalta a relevância da pesquisa aqui realizada.

Com a crescente expansão do mercado de turismo no país, evidencia-se cada vez mais a necessidade de compreender o comportamento dos usuários da Internet quanto ao uso de novas tecnologias, inclusive associadas ao turismo. Para tanto, foi desenvolvida essa pesquisa, junto a 251 usuários da Internet, participantes de grupos de Turismo presentes na rede social Facebook. 0 presente estudo traz importantes contribuições para o campo de conhecimento do Turismo e da Administração, mais especificamente na área de gestão de Tecnologia da Informação (TI) e Comportamento do consumidor de produtos de turismo online. Ao analisar diferentes fatores que influenciam a participação dos usuários no e-turismo, propôs-se um modelo causal que contribui com estudos anteriores identificados na literatura que também avaliaram empresas de turismo online, considerando, entretanto, diferentes antecedentes da confiança. Mais especificamente nesta pesquisa, buscou-se analisar a influência de antecedentes baseados nas características do website (medida através da Qualidade do site), da empresa (medida através da Reputação), da informação de terceiros (medida pelo e-WOM) e do consumidor (medido pela Satisfação com experiências prévias), propondo, ainda, a inclusão do produto turístico como outra característica que influencia a participação dos usuários no e-turismo - medida através da Qualidade percebida do produto.

Os resultados apontaram a satisfação com experiências prévias e a qualidade dos produtos turísticos como os principais aspectos que influenciam a intenção de comprar e recomendar o site, destacando-se o primeiro como o principal preditor da participação dos consumidores no e-turismo. Nesse sentido, quando o cliente apresenta experiências positivas com uma dada empresa de turismo, maior será a sua disposição para recomendá-la e comprar um produto turístico neste site futuramente. 
Em termos gerenciais, as empresas que oferecem produtos turísticos deveriam elaborar estratégias de modo a atrair potenciais clientes a visitarem seu site e, após a experiência de compra, criar relações positivas entre eles, seja através da oferta de descontos ou cupons de compra. Complementarmente, devido ao fato do produto turístico ser altamente intangível, caberia a estas empresas proporcionarem um maior relacionamento com os consumidores, preocupando-se em construir uma imagem mais concreta na mente dos usuários sobre o produto ou serviço turístico oferecido - seja proporcionando maiores detalhes sobre eles, por meio de fotos, relatos, descrições e informações sobre o destino, ou produto/serviço ofertado.

Ainda que a amostra desse estudo não seja probabilística, o que sugere cuidados quanto à generalização dos resultados, é possível destacar alguns dados referentes ao comportamento dos participantes do estudo como potenciais consumidores de produtos ou serviços turísticos online. Com relação às questões ligadas aos seus hábitos, evidenciou-se o quanto a marca da empresa se mostra como uma importante característica na escolha de um site de turismo online. Apesar das respostas dos participantes do estudo sugerirem a presença e o uso de uma grande variedade de sites de turismo online, os mais utilizados e citados pelos respondentes foram o Booking.com, o Decolar e o TripAdvsisor, sites bem conhecidos, de boa reputação e já consolidados no mercado.

Outro dado interessante foi que a grande maioria dos participantes indicou como hábito viajar acompanhado. Esta informação pode ser relevante para as agências de viagens e hotéis ao organizarem promoções e elaborarem produtos turísticos específicos a este grupo de consumidores, fora as ações de marketing que podem ser implementadas para atrair ou até mesmo fidelizar seus clientes. Adicionalmente, a pesquisa traz alguns indícios interessantes sobre os preços dos produtos oferecidos nos sites de turismo. A maioria dos respondentes afirmou que o site escolhido para fazer a sua avaliação apresentava preços um pouco mais baratos que o dos sites concorrentes, evidenciando que no turismo uma grande diferença de preço entre uma empresa e outra pode não ser determinante na escolha do produto turístico, até mesmo porque o preço também está associado à qualidade do produto. Isso sugere que os consumidores tendem a levar em consideração outros fatores na hora dessa escolha, fazendo uma análise de custo-benefício entre um ou outro produto disponível.

As descobertas aqui obtidas aprofundam a compreensão acerca das atitudes dos consumidores de produtos e serviços de turismo online, servindo de referência para gestores e também para o desenvolvimento de novos estudos. Espera-se, portanto, auxiliar tanto acadêmicos quanto praticantes interessados no estudo e na adoção de iniciativas relacionadas ao turismo eletrônico. Os resultados aqui identificados poderão ajudar empreendedores e gestores de empresas de turismo online a desenvolver estratégias que melhorem sua relação com os usuários da Internet e, consequentemente, influenciem suas atitudes ou intenções de comprar produtos ou serviços relacionados a viagens através deste canal, tendo em vista que o novo turista tem sido fortemente influenciado pelos avanços tecnológicos.

Dentre as limitações do estudo, pode-se destacar a forma de seleção da amostra e o baixo retorno dos respondentes que fazem parte de comunidades relacionadas a viagens e turismo. Tal fragilidade sugere cuidados quanto à generalização dos resultados da pesquisa. Como sugestões para trabalhos futuros, identificadas a partir de lacunas teóricas e de alguns resultados empíricos aqui obtidos, sugere-se (i) avaliar o uso do smartphone na busca de informações sobre eventos, locais turísticos, hospedagem e alimentação quando o turista já se encontra no local ou destino turístico e (ii) analisar a influência das mídias sociais no comportamento do turista, seja escolhendo um destino, adquirindo um produto turístico ou optando por uma ou outra empresa de turismo online.

\section{REFERÊNCIAS}

Agag, G., \& El-Masry, A. (2017). Why do consumers trust online travel websites? Drivers and outcomes of consumer trust toward online travel websites. Journal of Travel Research, 56(3), 347-369. https://doi.org/10.1177/0047287516643185

Alcántara-Pilar, J., Blanco-Encomienda, F., Armenski, T., \& Del Barrio-García, S. (2018). The antecedent role of online satisfaction, perceived risk online, and perceived website usability on the affect towards travel destinations. Journal of Destination Marketing \& Management, 9, 20-35. https://doi.org/10.1016/i.jdmm.2017.09.005

Alves, C. A., Stefanini, C. J., Silva, L. A., \& Moretti, S. L. (2018). O papel da experiência de compra na intenção de recompra. Revista Ciências Administrativas ou Journal of Administrative Sciences, 24(2). https://doi.org/10.5020/2318-0722.2018.6393 
Antón, C., Camarero, C., \& Laguna-García, M. (2017). Towards a new approach of destination loyalty drivers: Satisfaction, visit intensity and tourist motivations. Current Issues in Tourism, 20(3), 238-260. https://doi.org/10.1080/13683500.2014.936834

Bagozzi, R. P. (1981). Attitudes, intentions, and behavior: A test of some key hypotheses. Journal of Personality and Social Psychology, 41(4), 607. https://doi.org/10.1037/0022-3514.41.4.607

Bassani, M., Milan, G., Lazzari, F., \& De Toni, D. (2018). O Efeito País de Origem na Avaliação de Cervejas Especiais e na Intenção de Compra dos Consumidores: Um Estudo Experimental. Revista Brasileira de Marketing, 17(2), 278-295. https://doi.org/10.5585/remark.v17i2.3727

Beldad, A., De Jong, M., \& Steehouder, M. (2010). How shall I trust the faceless and the intangible? A literature review on the antecedents of online trust. Computers in Human Behavior, 26(5), 857-869. https://doi.org/10.1016/j.chb.2010.03.013

Biz, A., \& Correa, C. (2016). Abordagem brasileira sobre turismo e tecnologias da informação e comunicação: 10 anos de produção do Seminário da ANPTUR. Revista Turismo \& Desenvolvimento (RT\&D)/Journal of Tourism \& Development, 26.

Brasil. Ministério do Turismo (2014). A importância da internet para o turismo. Viajantes se apoiam nas redes sociais para definir o roteiro, organizar a viagem e compartilhar informações. Disponível em: http://www.turismo.gov.br/ultimas-noticias/2872-a-importancia-da-internet-para-o-turismo.html. Acesso em: 1 nov. 2018. .

Brasil. Ministério do Turismo (2018). Anuário Estatístico de Turismo - 2018 - ano base 2017. Disponível em: http://www.dadosefatos.turismo.gov.br/2016-02-04-11-53-05/item/366-anu\%C3\%A1rio-estat\%C3\%ADstico-de-turismo-2018-ano-base-2017/366-anu\%C3\%A1rio-estat\%C3\%ADstico-de-turismo2018-ano-base-2017.html. Acesso em: 15 fev. 2019.

Buhalis, D., \& Deimezi, O. (2004). E-tourism developments in Greece: Information communication technologies adoption for the strategic management of the Greek tourism industry. Tourism and Hospitality Research, 5(2), 103-113. https://doi.org/10.1057/palgrave.thr.6040011

Buhalis, D., \& Law, R. (2008). Progress in information technology and tourism management: 20 years on and 10 years after the Internet - The state of eTourism research. Tourism Management, 29(4), 609-623. https://doi.org/10.1016/j.tourman.2008.01.005

Carvalho, D. T., Ferreira, L. B., Kanazawa, F. N., Machado, P. M., \& Giraldi, J. D. M. E. (2016). Experiência em website de marca-país e a formação da imagem de destino turístico: um estudo na Islândia. Revista Brasileira de Pesquisa em Turismo, 10(1), 108-128. https://doi.org/10.7784/rbtur.v10i1.1019

Cechinel, E., \& Santos, A. R. (2018). Comi, Gostei e Postei: Tripadvisor e Experiências Marcantes em Restaurantes. Rosa dos Ventos-Turismo e Hospitalidade, 10(3). https://doi.org/10.18226/21789061.v10i3p538

Chang, H., \& Chen, S. (2008). The impact of online store environment cues on purchase intention: trust and perceived risk as a mediator. Online Information Review, 32 (6), 818-841. https://doi.org/10.1108/14684520810923953

Cosma, S., Bota, M., \& Tutunea, M. (2012). Study about customer preferences in using online tourism Products. Procedia Economics and Finance, 3, 883-888. https://doi.org/10.1016/S2212-5671(12)00245-6

Dedeke, A. (2016). Travel web-site design: Information task-fit, service quality and purchase intention. Tourism Management, 54, 541-554. https://doi.org/10.1016/j.tourman.2016.01.001

Di Pietro, L., Di Virgilio, F., \& Pantano, E. (2011). Social network for the choice of tourist destination: attitude and behavioural intention. Journal of Hospitality and Tourism Technology, 3(1), 60-76. https://doi.org/10.1108/17579881211206543

Fernández-Poyatos, M., \& Papí-Gálvez, N. (2017). eTurismo: estudio de criterios de segmentación clásicos del usuario online que compra por internet. Revista ICON014 Revista Científica de Comunicación y Tecnologías Emergentes, 15(2), 168-189. https://doi.org/10.7195/ri14.v15i2.1066

Filieri, R., Alguezaui, S., \& McLeay, F. (2015). Why do travelers trust TripAdvisor? Antecedents of trust towards consumer-generated media and its influence on recommendation adoption and word of mouth. Tourism Management, 51, 174-185. https://doi.org/10.1016/j.tourman.2015.05.007 
Forgas-Coll, S., Palau-Saumell, R., Matute, J., \& Tárrega, S. (2017). How do service quality, experiences and enduring involvement influence tourists' behavior? An empirical study in the Picasso and Miró Museums in Barcelona. International Journal of Tourism Research, 19(2), 246-256. https://doi.org/10.1002/jtr.2107

Hair, J. F., Jr., Black, W. C., \& Babin, B. J. (2009). Multivariate data analysis.7th ed. Englewood Cliffs, NJ: Prentice Hall.

Hair Jr, J., Risher, J., Sarstedt, M., Ringle, C. (2019). When to use and how to report the results of PLS-SEM. European Business Review, 31(1), 2-24. https://doi.org/10.1108/EBR-11-2018-0203

Hair Jr, J., Sarstedt, M., Hopkins, L., \& G. Kuppelwieser, V. (2014). Partial least squares structural equation modeling (PLS-SEM) An emerging tool in business research. European Business Review, 26(2), 106-121. https://doi.org/10.1108/EBR-10-2013-0128

Hair Jr, J. F.; Sarstedt, M.; Ringle, C. M.; Gudergan, S. P. (2017). Advanced Issues in Partial Least Squares Structural Equation Modeling. SAGE Publications. https://doi.org/10.1007/978-3-319-05542-8 15-1

Hajli, M., Hajli, M., \& Khani, F. (2013, April). Establishing trust in social commerce through social word of mouth. In 7th International Conference on e-Commerce in Developing Countries: with focus on e-Security (pp. 1-22). IEEE. https://doi.org/10.1109/ECDC.2013.6556738

Herrero, Á., San Martín, H., \& Hernández, J. (2015). How online search behavior is influenced by user-generated content on review websites and hotel interactive websites. International Journal of Contemporary Hospitality Management, 27(7), 1573-1597. https://doi.org/10.1108/IJCHM-05-2014-0255

Huang, Z., \& Benyoucef, M. (2013). From e-commerce to social commerce: A close look at design features. Electronic Commerce Research and Applications, 12(4), 246-259. https://doi.org/10.1016/j.elerap.2012.12.003

Jaremen, D. (2016). Advantages from ICT usage in Hotel Industry. Czech Journal of Social Sciences Business and Economics, 5(3), 6-18. https://doi.org/10.24984/cjssbe.2016.5.3.1

Keh, H., \& Xie, Y. (2009). Corporate reputation and customer behavioral intentions: The roles of trust, identification and commitment. Industrial Marketing Management, 38(7), 732-742.

https://doi.org/10.1016/j.indmarman.2008.02.005

Kim, S., \& Park, H. (2013). Effects of various characteristics of social commerce (s-commerce) on consumers' trust and trust performance. International Journal of Information Management, 33(2), 318-332. https://doi.org/10.1016/j.ijinfomgt.2012.11.006

Kim, S., Kandampully, J., \& Bilgihan, A. (2018). The influence of eWOM communications: An application of online social network framework. Computers in Human Behavior, 80, 243-254. https://doi.org/10.1016/j.chb.2017.11.015

Lehto, X., Kim, D., \& Morrison, A. (2006). The effect of prior destination experience on online information search behaviour. Tourism and Hospitality Research, 6(2), 160-178. https://doi.org/10.1057/palgrave.thr.6040053.

Leung, D., Law, R., Van Hoof, H., \& Buhalis, D. (2013). Social media in tourism and hospitality: A literature review. Journal of Travel \& Tourism Marketing, 30(1-2), 3-22.

https://doi.org/10.1080/10548408.2013.750919

Liao, Z., \& Shi, X. (2017). Web functionality, web content, information security, and online tourism service continuance. Journal of Retailing and Consumer Services, 39, 258-263. https://doi.org/10.1016/i.jretconser.2017.06.003

Liu, X., He, M., Gao, F., \& Xie, P. (2008). An empirical study of online shopping customer satisfaction in China: a holistic perspective. International Journal of Retail \& Distribution Management, 36(11), 919-940. https://doi.org/10.1108/09590550810911683

Maia, C. R. (2019). Os efeitos da marca e dos componentes do comércio social na confiança e intenção de compra de consumidores de agências de viagens online. 2019. Dissertação (Mestrado em Administração) - Universidade Federal do Rio Grande/RS.

Marchiori, E., \& Cantoni, L. (2015). The role of prior experience in the perception of a tourism destination in user-generated content. Journal of Destination Marketing \& Management, 4(3), 194-201.

https://doi.org/10.1016/i.jdmm.2015.06.001 
Navío-Marco, J., Ruiz-Gómez, L., \& Sevilla-Sevilla, C. (2018). Progress in information technology and tourism management: 30 years on and 20 years after the internet-Revisiting Buhalis \& Law's landmark study about eTourism. Tourism Management, 69, 460-47. https://doi.org/10.1016/j.tourman.2018.06.002

Nilashi, M., Ibrahim, O., Yadegaridehkordi, E., Samad, S., Akbari, E., \& Alizadeh, A. (2018). Travelers decision making using online review in social network sites: A case on TripAdvisor. Journal of Computational Science, 28, 168-179. https://doi.org/10.1016/i.jocs.2018.09.006

Olsen, L., \& Johnson, M. (2003). Service equity, satisfaction, and loyalty: from transaction-specific to cumulative evaluations. Journal of Service Research, 5(3), 184-195. https://doi.org/10.1177/1094670502238914

Oneto, A., Ferreira, J., Giovannini, C., \& da Silva, J. (2015). Confiança e satisfação na compra de turismo online. Revista Brasileira de Pesquisa em Turismo, 9(2), 221-239. https://doi.org/10.7784/rbtur.v9i2.738

Öz, M. (2015). Social media utilization of tourists for travel-related purposes. International Journal of Contemporary Hospitality Management, 27(5), 1003-1023. https://doi.org/10.1108/IJCHM-01-2014-0034

Ponte, E., Carvajal-Trujillo, E., \& Escobar-Rodríguez, T. (2015). Influence of trust and perceived value on the intention to purchase travel online: Integrating the effects of assurance on trust antecedents. Tourism Management, 47, 286-302. https://doi.org/10.1016/j.tourman.2014.10.009

Ramos, C. (2008). A integração dos sistemas de informação e do turismo, o caso IMPACTUR. In: CONFERÊNCIA DA ASSOCIAÇÃO PORTUGUESA DE SISTEMAS DE INFORMAÇÃO, 8., 2008. Anais...

Rodríguez-Díaz, M., Rodríguez-Voltes, C., \& Rodríguez-Voltes, A. (2018). Gap analysis of the online reputation. Sustainability, 10(5), 1603. https://doi.org/10.3390/su10061953

Santos, B. R., \& Perinotto, A. R. C. (2016). Museu virtual: análise de suas potencialidades como ferramenta de comunicação turística. Turydes Revista Turismo y Desarrollo, 20. https://doi.org/10.5902/2316882X22791

Santos, S., Souza Neto, V., Pereira, L., Gândara, J., \& Silva, S. (2016). Destino turístico inteligente: acessibilidade no centro histórico de São Luís-Maranhão, um estudo sobre a reputação online no TripAdvisor. Marketing \& Tourism Review, 1(2). https://doi.org/10.29149/mtr.v1i2.3843

Sharma, P., \& Nayak, J. (2019). Understanding memorable tourism experiences as the determinants of tourists' behaviour. International Journal of Tourism Research, 21(4), 504-518. https://doi.org/10.1002/jtr.2278

Silva, D.; Mendes-Filho, L, \& Corrêa, C. (2017). Comentários de Viagem na Internet: Fatores que influenciam a intenção de escolha de um destino de viagem. Revista de Turismo y Patrimonio Cultural, 15(1), 229-244. https://doi.org/10.25145/j.pasos.2017.15.014

Sullivan, Y., \& Kim, D. (2018). Assessing the effects of consumers' product evaluations and trust on repurchase intention in e-commerce environments. International Journal of Information Management, 39, 199219. https://doi.org/10.1016/j.ijinfomgt.2017.12.008

Ukpabi, D., \& Karjaluoto, H. (2017). Consumers' acceptance of information and communications technology in tourism: A review. Telematics and Informatics, 34(5), 618-644. https://doi.org/10.1016/j.tele.2016.12.002

Valle, P., \& Assaker, G. (2016). Using Partial Least Squares Structural Equation Modeling in Tourism Research: A Review of Past Research and Recommendations for Future Applications. Journal of Travel Research, 55, 695-708. https://doi.org/10.1177/0047287515569779

Xia, M., Zhang, Y., \& Zhang, C. (2018). A TAM-based approach to explore the effect of online experience on destination image: A smartphone user's perspective. Journal of Destination Marketing \& Management, 8 , 259-27. https://doi.org/10.1016/j.jdmm.2017.05.002

Xiang, Z., Magnini, V., \& Fesenmaier, D. (2015). Information technology and consumer behavior in travel and tourism: Insights from travel planning using the internet. Journal of Retailing and Consumer Services, 22, 244-249. https://doi.org/10.1016/j.jretconser.2014.08.005

Zhang, Y., Fang, Y., Wei, K., Ramsey, E., McCole, P., \& Chen, H. (2011). Repurchase intention in B2C e-commerce - a relationship quality perspective. Information \& Management, 48(6), 192-200.

https://doi.org/10.1016/j.im.2011.05.003 


\section{Informações dos autores}

\section{Fernanda dos Santos}

Graduada em Administração pela Universidade Federal do Rio Grande (2019). Possui experiência de pesquisa na área de Tecnologia da Informação e Comunicação, Estatística e Turismo Online.

Contribuiu para concepção da pesquisa, revisão da literatura, coleta de dados, análise de dados, discussão dos resultados.

Email: fer.0108.santos@hotmail.com

ORCID: https://orcid.org/0000-0002-4655-7985

\section{Guilherme Lerch Lunardi}

Possui graduação em Administração - Hab. Empresas pela Universidade Federal do Rio Grande - FURG (1999), mestrado em Administração pela Universidade Federal do Rio Grande do Sul (2001) e doutorado em Administração pela Universidade Federal do Rio Grande do Sul (2008). Em 2013, fez pós-doutorado na Ecole des Hautes Etudes Commerciales de Montreal/Canadá (HEC-Montreal). É professor Associado II da Universidade Federal do Rio Grande e participa como professor permanente do Programa de Pós-Graduação em Administração da FURG - Mestrado Acadêmico em Administração (PPGA/FURG) e Mestrado Profissional em Administração Pública (PROFIAP/FURG). Tem experiência na área de Administração, com ênfase em Sistemas de Informação, atuando principalmente nos seguintes temas: impacto de TI, bancos, tecnologia de informação, governança de TI, TI Verde e Tecnologias da Informação aplicada à Saúde.

Contribuiu para concepção da pesquisa, revisão da literatura, coleta de dados, análise de dados, discussão dos resultados.

Email: gllunardi@furg.br

ORCID: https://orcid.org/0000-0003-3250-2796

\section{Cláudia Rodrigues Maia}

Doutoranda em Administração, na área de Marketing da Universidade Federal do Rio Grande - PPGA/UFRGS. Mestra em Administração, na área de Tecnologias Gerenciais, pelo Programa de Pós-Graduação em Administração PPGA/FURG (2019). Graduada em Administração pela Universidade Federal do Rio Grande (2016). Possui experiência de pesquisa na área de Tecnologia da Informação, TI verde, Comércio Social, Comércio Móvel e Turismo Online.

Contribuiu para concepção da pesquisa, revisão da literatura, coleta de dados, análise de dados, discussão dos resultados.

Email: claudiarmaia@hotmail.com

ORCID: https://orcid.org/0000-0002-7274-0118

\section{Edar da Silva Añaña}

Possui Doutorado em Administração pela Universidade Federal do Rio Grande do Sul (2008), com estágio doutoral no Instituto de Turismo da Universidade de Economia e Administração de Viena-Áustria (Wirtschaftsuniversität Wien); Mestrado em Administração pela Universidade Federal do Rio Grande do Sul (2001); e graduação em Administração pela Universidade da Região da Campanha (1986). Atualmente é Professor Adjunto da Universidade Federal de Pelotas e Pesquisador apoiado pelo CNPq. Atua, principalmente, nas linhas de pesquisa de Marketing, Comportamento do consumidor e turismo.

Contribuiu para análise de dados, discussão dos resultados.

Email: edaranana@gmail.com

ORCID: https://orcid.org/0000-0002-8298-9208 
Anexo - Itens do questionário utilizados na pesquisa

\begin{tabular}{|c|c|c|c|}
\hline Indicadores & $\mathrm{n}$ & Média & $\begin{array}{l}\text { Desvio } \\
\text { Padrão }\end{array}$ \\
\hline Reputação - adaptado de Kim e Park (2013) & 251 & 6,35 & 0,81 \\
\hline REPUT1. Esta empresa de turismo online é bem conhecida* & 250 & 6,45 & 1,00 \\
\hline REPUT2. Esta empresa de turismo online tem uma boa reputação & 249 & 6,29 & 0,99 \\
\hline REPUT3. Esta empresa de turismo online tem reputação de ser honesta & 251 & 6,20 & 1,10 \\
\hline REPUT4. Estou familiarizado com o nome desta empresa de turismo online & 251 & 6,45 & 1,03 \\
\hline Satisfação com Experiências Prévias- adaptado de Liu et al. (2008); Filieri et al.(2015) & 251 & 6,32 & 0,86 \\
\hline $\begin{array}{l}\text { EXP1. Se eu tivesse que fazer tudo de novo, eu faria minha compra ou busca novamente neste } \\
\text { site }\end{array}$ & 251 & 6,34 & 1,05 \\
\hline EXP2. Minha(s) experiência(s) de busca/compra neste site foi boa & 251 & 6,40 & 0,87 \\
\hline EXP3. Eu realmente gostei da experiência de busca/compra neste site & 251 & 6,24 & 1,01 \\
\hline EXP4. Minha(s) experiência(s) com compras neste site foi satisfatória & 251 & 6,31 & 1,03 \\
\hline Qualidade do WebSite - adaptado de Filieri et al. (2015) & 251 & 6,08 & 0,88 \\
\hline SITE1. Este site é fácil de navegar & 251 & 6,38 & 0,91 \\
\hline SITE2. Este site tem links bem organizados & 250 & 6,05 & 1,14 \\
\hline SITE3. Este site tem alta velocidade de carregamento da página & 251 & 5,83 & 1,25 \\
\hline SITE4. Este site é fácil de acessar em diferentes dispositivos & 249 & 6,06 & 1,20 \\
\hline e-WOM - adaptado de Maia (2019) & 251 & 5,93 & 1,03 \\
\hline $\begin{array}{l}\text { eWOM1. O site apresenta bons comentários e avaliações sobre a empresa e seus produtos } \\
\text { ofertados }\end{array}$ & 250 & 5,94 & 1,34 \\
\hline eWOM2. As avaliações online disponiveis neste site são positivas & 251 & 5,98 & 1,08 \\
\hline $\begin{array}{l}\text { eWOM3. Os comentários e avaliações disponíveis no site são bem favoráveis à empresa e seus } \\
\text { produtos }\end{array}$ & 250 & 5,94 & 1,15 \\
\hline eWOM4. O site apresenta comentários e avaliações benéficas sobre a empresa e seus produtos & 251 & 5,85 & 1,30 \\
\hline Qualidade do Produto - adaptado de Dedeke (2016) & 251 & 5,84 & 0,89 \\
\hline PROD1. Os produtos e pacotes oferecidos neste site são atrativos & 250 & 5,96 & 1,01 \\
\hline PROD2. Os produtos e pacotes oferecidos neste site são de alta qualidade & 250 & 5,96 & 1,00 \\
\hline $\begin{array}{l}\text { PROD3. Os produtos e pacotes oferecidos neste site parecem proporcionar experiências dura- } \\
\text { douras }\end{array}$ & 251 & 5,72 & 1,25 \\
\hline PROD4. Os produtos e pacotes oferecidos neste site são bem elaborados & 248 & 5,72 & 1,26 \\
\hline Intenção de compra - adaptado de Kim e Park (2013) & 250 & 6,08 & 1,12 \\
\hline INT1. Estou propenso a comprar produtos ou pacotes turísticos neste site & 250 & 6,18 & 1,14 \\
\hline INT2. É provável que eu vá comprar algum produto ou pacote turístico neste site em breve & 249 & 5,87 & 1,35 \\
\hline $\begin{array}{l}\text { INT3. Dada a oportunidade, tenho a intenção de comprar algum produto ou pacote turístico } \\
\text { neste site futuramente }\end{array}$ & 250 & 6,19 & 1,22 \\
\hline Recomendar - adaptado de Kim e Park (2013) & 251 & 5,74 & 1,46 \\
\hline REC1. Mencionei este site a várias pessoas que buscavam informações sobre viagens & 251 & 5,62 & 1,58 \\
\hline REC2. Falei positivamente sobre este site de viagens para várias pessoas & 250 & 5,85 & 1,49 \\
\hline REC3. Recomendei este site de viagens para amigos próximos & 250 & 5,75 & 1,52 \\
\hline
\end{tabular}

* item eliminado após os procedimentos de validação 